views. If the book is intended for junior surgeons in training then labelling on the photographs, or line diagrams alongside are essential to help with identification, which after all is the difficult part of any operation. It seems that some of the photographs have been taken with different film or processed in a different way from others. Sometimes the pictures add little, if anything, to the description.

In summary, this is a good description of a common major procedure by an experienced and accomplished gastric surgeon but there are certainly defects in the photographic presentation; this is the responsibility of the author and publishers as well as the photographers. At $£ 14$ it is reasonably priced.

\section{V MANN}

Reconstructive surgery of the gastrointestinal tract Edited by Alfred Cuschieri and David B Skinner. (Pp. 289; illustrated; £40·00.) Sevenoaks, Kent: Butterworths, 1985.

A book that will be welcomed by surgeons to provide guidance in some of the more difficult problems of gastrointestinal surgery. The general principles should be mandatory reading for all Fellowship candidates.

Many surgeons will disagree with some of the views expressed and in the treatment of reflux it was disappointing to see no reference (even to dismiss it) to the Angelchick prosthesis. This chapter and the one on oesophageal reconstruction is dominated by the Belsey/Skinner views. The chapter on post gastric surgery syndromes is a little too brief and in some areas would have benefited from the more critical analysis.

There is a section on ileostomy and colostomy and restoration of bowel continuity which is a little disappointing in that it adds nothing new but the sections on colorectal surgery with sphincter preservation, anterior resection and the treatment of prolapse and faecal incontinence are all well worth reading.

There is an excellent review of congenital disorders of the gastrointestinal tract and this is probably the best section I have seen for the Fellowship candidate. The book as a whole should find its place in every general library and no committed gastrointestinal surgeon should be without it.

C G CLARK

Laparoskopie: Atlas and Lehrbuch By H Henning and D Look. (Pp. 278; illustrated; DM 268.) Stuttgart, New York: Georg Thieme Verlag, 1985. It is unusual for a German publication to be less than all-embracing and this book is no exception. The first part, running to about 100 pages, covers indications, a comparison of laparoscopy with other methods of investigation, contraindications, laparoscopy in special situations for example, when adhesions are present, complications, and even veterinary laparoscopy. Gynaecological laparoscopy is mentioned only briefly. There are also chapters on the requirements of a laparoscopy theatre, much detail on equipment, preparation and aftercare of the patient and of course a detailed description of the procedure, and further shorter sections on such topics as documentation. The second part, of over 150 pages, is a lavishly and beautifully illustrated atlas, each illustration being accompanied by a short description. Throughout the book there are tables and diagrams, mostly presented in attractive pastel shades and loaded with information. The references, which are listed alphabetically and are not numbered, seem to add up to over 1500 .

The approach, is, clearly, comprehensive. The overall appearance of the book is excellent, and the layout and printing of a very high standard. The photographs of laparoscopic appearances are outstanding and especially impressive to those of us who are more used to seeing photographs of fibreendoscopic appearances. The authors and publishers are to be congratulated on producing a book which will for long remain the reference book on this subject.

In 1970-73 over 90000 laparoscopies were carried out in Germany, while in the rest of Europe only approximately 52000 were reported. Do we do too few of these investigations? Certainly this book will help us review and possibly revise our ideas. The German edition costs DM 268. An English edition is promised for 1986 . It will be very welcome.

K F R SCHILLER

Sterols and bile acids. Edited by $\mathrm{H}$ Danielsson and $\mathrm{J}$ Sjovall. (Pp. 447; illustrated; US\$70.00; DFl 189.00.) Amsterdam: Elsevier Science Publishers, 1985.

This is a beautifully produced book forming volume 12 of the New comprehensive biochemistry series. Not surprisingly, therefore, the majority of the book is devoted to basic biochemistry and may have limited appeal to practising gastroenterologists. The editors are distinguished scientists well known in the field. There are 14 chapters, the first six being primarily devoted to the biochemistry of cholesterol (biosynthesis, control of uptake, carrier proteins, esters, absorption, and metabolism by intestinal epithelium, and involvement in membrane structure). Chapters 9-14 deal with the biosynthesis and metabolism of bile acids. There is one chapter on plant sterols, one on sterols in invertebrates and a 
third on bile alcohols and primitive bile acids. There are two chapters which may have particular clinical appeal. First, chapter 5, dealing with cholesterol absorption and metabolism by the intestinal epithelium, discusses cholesterol absorption and synthesis, uptake of lipoproteins, cholesterol esterification, secretion of cholesterol into intestinal lymph and compartmentalisation of cholesterol. Second, chapter 14 which discusses the role of bile acids in intestinal lipid digestion and absorption, and reminds us that bile acids are not obligatory for the absorption of triglycerides but may be required for the absorption of other lipids such as cholesterol. Most chapters give extensive references up until 1983. There are a few references to original research in 1985 and 1986 although these are usually selfcitations. There are 20 pages of indexing, containing around 1600 entries. As a biochemist I liked this book and although I searched for mistakes, I could find very few. A gastroenterologist needing a biochemical background to cholesterol and its metabolism (excluding steroid hormones), would find this a useful and accurate reference text. Unfortunately like all such books, it will rapidly become outdated as knowledge in this area increases.

H L J MAKIN

\section{News}

\section{British Society of Gastroenterology}

The 1986 Autumn Meeting of the British Society of Gastroenterology was held under the presidency of Dr G P Crean in Cardiff on 24-26 September, 1986; 108 free papers and 100 posters were selected for presentation in the scientific sessions. The plenary session was held in the St David's Hall and concluded with the Sir Arthur Hurst Lecture which was given by Dr K G Wormsley on 'Alimentary carcinogenesis'. The Endoscopy Foundation Lecture was given by Professor G Vantrappen, and the meeting included four 'State of the Art' lectures. Generous commercial sponsorship enabled a varied social programme centred on Cardiff Castle; the latter accommodated not only simultaneous but separate banquets for endoscopists and hepatologists, but also, on the following evening, the annual dinner which was held in a marquee on the Castle Green. 21st Annual Scientific Meeting of the European Society for Clinical Investigation

This meeting will take place in Elsinore, Denmark from 21-24 March, 1987. Further details from ESCI-87, c/o D I Barry, Department of Psychiatry, 0 6234, Rigshospitalet - Blegdamsvej 9, DK 2100 Copenhagen, Denmark.

\section{American Board of Internal Medicine}

1987 Subspecialty examinations in gastroenterology and critical care medicine. Registration period: 1 January - 1 April 1987. Examination date: 10 November 1987. Further information from the Registration Section, American Board of Internal Medicine, 3624 Market Street, Philadelphia, Pennsylvania 19104, USA.

\section{Course in Gastroenterology, Oxford}

Six bursaries, each to the value of $£ 160$ will be available to British applicants of senior registrar or lecturer status, who are undergoing higher medical training in gastroenterology. Further details of the course and applications for the bursaries (including a CV) should be made to Dr D P Jewell, Radcliffe Infirmary, Oxford OX2 6HE.

International Symposium on the Immunology of the Gastrointestinal Tract and the Liver

This symposium will be held at the Laromme Hotel, Jerusalem, Israel from 22-27 March, 1987. Further details from International Ltd, 12, Shlomzion Hamalka Street, Jerusalem 94 146, Israel, quoting the title of the symposium.

Fifth Annual Hawaii Conference on Gastrointestinal and Hepatic Diseases

This conference will be held at the Hyatt Regency Hotel, Maui, Hawaii from 26-30 January, 1987. Further information from Dr G Glober, Gastro '87, 1380 Lusitana Street, no 701, Honolulu, Hawaii.

\section{International Symposium on Vasopressin Analogs} and Portal Hypertension

This symposium will take place at the Montparnasse Park Hotel, Paris on 10 April 1987. Further details from Laboratories Ferring SA, Sophie Battarel, 7, rue des Cordelières, Paris, France.

Fifth Course in Hepatobiliary Surgery

This course will be held at the Royal Postgraduate Medical School, London from 10-14 November 1986. Details from the School Office, RPMS, Ducane Road, London, W12 0HS. 